\title{
Cytomegalovirus (CMV) Encephalitis in HIV Patients
}

Manasa Velagapudi, Cherry Onaiwu, Vritti Gupta, Jennifer Anthone, Lauren Bricker, Allen Ameri and Renuga Vivekanandan*

Department of Medicine, Infectious Disease Fellowship, Creighton University Medical Center, USA

*Corresponding author: Renuga Vivekanandan, Department of Medicine, Infectious Disease Fellowship, Creighton University Medical Center, 601 North 30th Street, Suite 5800, Omaha, NE 68131, USA, Tel: 402-280-4191; E-mail: renuga.vivekanandan@alegent.org

Rec date: Oct 26, 2016; Acc date: Nov 15, 2016; Pub date: Nov 20, 2016

Copyright: @ 2016 Velagapudi M, et al. This is an open-access article distributed under the terms of the Creative Commons Attribution License, which permits unrestricted use, distribution, and reproduction in any medium, provided the original author and source are credited.

\section{Mini Review}

In HIV patients with low CD4 count, CMV is a significant cause of morbidity and mortality.

It is hypothesized that impaired CD4 cell functioning is attributable to viral replication. Most cases of CMV encephalitis occur when CD4 counts fall below 50, however patients may be predisposed to CMV infection prior to depletion of CD4 [1]. Previous opportunistic infections (OIs), a high level of CMV viremia, and high plasma HIV RNA levels (>100,000 copies $/ \mathrm{mL}$ ) are other reported risk factors [2].

Many studies have reported that the incidence of CNS infections in HIV patients has decreased and mortality has improved since the introduction of ART [3-7]. Neunberg et al reports a decreased in rate of CMV encephalitis from $21.9 \%$ before 1987 , to $9.5 \%$ after the introduction of ART [6]. With antiretroviral therapy (ART), the median survival of patients with CMV encephalitis has improved by 3 months.

CMV encephalitis can also be characterized by: focal parenchymal necrosis, ventriculo-encephalitis with focal or diffuse destruction of ependymal lining and periventricular tissue [8]. Given the lack of typical clinical features in most of cases, clinical diagnosis of CMV encephalitis has been made in less than $2 \%$ of the patients, but $10 \%$ to $14 \%$ of the patients have been found to have CMV encephalitis on autopsy [9].

\section{Clinical Features of CMV Encephalitis}

CMV neuroinvasive disease in HIV manifests as retinitis, encephalitis or radiculomyelitis [10]. Autopsy studies have shown CMV retinitis in $32 \%$ [11], encephalitis in up to $30 \%$, but polyradiculomyelitis occurred in only $2 \%$ of patients with AIDS and neurological disease [12]. Diffuse encephalitis is the most common form and presents as dementia with neurologic symptoms of reduced memory, attention, and concentration although cranial nerve deficits, ataxia, hemiparesis and hemianopsia are also reported [13-15]. Often the presentation can be difficult to differentiate from HIV associated encephalopathy [16].

Ventriculoencephalitis is a more rapidly progressively form, often characterized by focal neurological signs, cranial nerve deficits and nystagmus, and lesser neuropsychological symptoms [2]. However, it may be very difficult to distinguish between ventriculoencephalitis and diffuse encephalitis solely on the basis of clinical features [13].

CMV myelitis is a form of necrotizing myelitis resulting in paraplegia or tetraplegia [10], whereas poyradiculo-myeloptahy manifests with ascending are flexia, hypotonic paresis, paresthesia's and early urinary retention [17-19].

\section{Diagnosis}

There are multiple modalities that can be utilized for the diagnosis of CMV encephalitis in HIV patients. One of the most sensitive and specific tests for diagnosis is analysis of the viral DNA and detection of pp65 in polymorphonuclear leukocytes of the CSF by PCR [20]. CMV infection will usually present with negative bacterial cultures and an increase in CSF WBC's that are predominantly neutrophils [21]. Studies have shown that imaging modalities are not highly sensitive for the detection of CMV encephalitis in HIV patients, however, periventricular inflammation and/or ventricular enhancement with or without ventriculomegaly are supportive findings [22]. In some confirmed cases, cortical atrophy and diffuse white matter hyperintensity on MRI has been reported [23]. CMV infected patients can also present with evidence of retinitis with fundoscopy demonstrating hemorrhagic infarction and retinal opacification [2].

\section{Treatment}

For HIV patients who develop CMV encephalitis, the recommended treatment regimen is combination IV therapy with ganciclovir $5 \mathrm{mg} / \mathrm{kg}$ every 12 hours and foscarnet $60 \mathrm{mg} / \mathrm{kg}$ every 8 hours (an alternative dosing to consider is $90 \mathrm{mg} / \mathrm{kg}$ every 12 hours) [2]. The recommendation for dual treatment is based on the high mortality rates seen in patients with CMV-related neurological disease [24-27]. Randomized controlled trials are lacking, so evidence primarily consists of case reports and extrapolation of data from CMV retinitis treatment. The available evidence indicates that treatment with ganciclovir and foscarnet together results in better outcomes than when either agent is used alone [24-29]. However, there is no established duration of treatment or recommendation for transition to maintenance therapy, so practice is generally influenced by trials of CMV retinitis or relapsed retinitis [6-8]. Induction therapy with both ganciclovir and foscarnet is at least 14 to 21 days but may be extended depending on clinical status and CSF studies [2,24,25]. Maintenance therapy may include lower doses of ganciclovir/foscarnet combination therapy, ganciclovir or foscarnet monotherapy, or valganciclovir monotherapy at $900 \mathrm{mg}$ orally daily [24-25]. Treatment should be continued until the CD4 count is greater than 100 cells $/ \mathrm{mm}^{3}$ for at least 6 months [2,24]. Ganciclovir is associated with neutropenia and thrombocytopenia, while foscarnet may cause renal toxicity [30]. These adverse effects can be dose limiting and require monitoring, especially with long durations of treatment [30].

\section{Drug Resistant CMV}

Drug-resistant isolates of CMV were first reported in 1989, but incidence has been reported as decreasing (28\% resistance prior to 1996 and 9\% since 1996) with the availability of effective ART in HIV/ AIDS patients [31,32]. The decline in reported resistance has been 
Page 2 of 3

attributed to better control of CMV replication with ART. Resistanceassociated mutations have been identified in the UL97 kinase gene and the UL54 DNA polymerase gene [31-36]. Resistance is characterized by an increase in drug concentration required to reduce the viral growth by $50 \%[33,34]$. Viral UL97 kinase gene mutations confer ganciclovir resistance, but viral UL54 DNA polymerase gene mutations can confer resistance to any of the standard anti-CMV antiviral agents (ganciclovir, foscarnet, and cidofovir) [34,35]. Resistance is unusual in the first six weeks of therapy, but should be suspected when persistent or increasing CMV viral loads are reported or progression of disease occurs after several weeks of appropriate anti-CMV therapy [33,36-38]. Treatment options are limited in this patient population, usually resulting in combination therapy with multiple antiviral agents - most commonly ganciclovir plus foscarnet [36]. If any UL97 mutation is present, foscarnet therapy is normally indicated. For UL97 mutations that result in low-grade resistance of ganciclovir, it may be possible to double the standard induction dose of ganciclovir to overcome resistance in clinically stable patients [39]. Cidofovir can also be considered in patients where ganciclovir resistance is only due to a UL97 mutation [33]. In patients with a UL54 mutation, high grade foscarnet resistance is rare but may confer low-grade ganciclovir with or without cidofovir cross resistance $[34,40]$. In patients with confirmed resistance to all standard anti-CMV or in those who are not clinically improving, other agents that have been used in the transplant population include: artesunate, maribavir, and leflunomide [41-43].

\section{Conclusion}

HIV patients who present with neurologic symptoms of reduced memory, attention, and concentration or sudden onset of mental status change high on the differential diagnosis should be CMV encephalitis. Early aggressive treatment with dual antiviral agents suggests better outcomes for the patients. Seek infectious disease /HIV specialist's expertise if available.

\section{References}

1. Schrier RD, Freeman WR, Wiley CA, McCutchan JA (1995) Immune predispositions for cytomegalovirus retinitis in AIDS. The HNRC Group. J Clin Invest 95: 1741-1746.

2. National Institute of Health (2016) HIV/AIDS Guidelines-AIDS info. Nov, 2016. Retrieved from http://aidsinfo.nih.gov/contentfiles/ lvguidelines/Adult_OI.pdf.

3. Collier AC, Coombs RW, Schoenfeld DA, Bassett R, Baruch A, et al. (1996) Combination therapy with zidovudine, didanosine and saquinavir. Antiviral Res 29: 99.

4. Kirk O, Reiss P, Uberti-Foppa, C, Bickel M, Gerstoft J, et al. (2002) Safe interruption of maintenance therapy against previous infection with four common HIV-associated opportunistic pathogens during potent antiretroviral therapy. Annals of Internal Medicine 137: 239-250.

5. San-Andrés FJ, Rubio R, Castilla J, Pulido F, Palao G, et al. (2003) Incidence of acquired immunodeficiency syndrome-associated opportunistic diseases and the effect of treatment on a cohort of 1115 patients infected with human immunodeficiency virus, 1989-1997. Clin Infect Dis 36: 1177-1185.

6. Neuenburg J, Brodt H, Herndier B, Bickel M, Bacchetti P, et al. (2002) HIV-related neuropathology, 1985 to 1999: Rising prevalence of HIV encephalopathy in the era of highly active antiretroviral therapy. Journal of Acquired Immune Deficiency Syndromes 31: 171-177.

7. Gallant JE, Moore RD, Richman DD, Keruly J, Chaisson RE (1992) Incidence and natural history of cytomegalovirus disease in patients with advanced human immunodeficiency virus disease treated with zidovudine. The Zidovudine Epidemiology Study Group. J Infect Dis 166: 1223-1227.

8. Ho M (1991) Cytomegalovirus: biology and infection. (2ndedn), Plenum Publishing Corporation. New York, NY.

9. Chaudhuri A, Kennedy PG (2002) Diagnosis and treatment of viral encephalitis. Postgrad Med J 78: 575-583.

10. Tan IL, Smith BR, Von Geldern G, Mateen FJ, McArthur JC (2012) HIVassociated opportunistic infections of the CNS. Lancet Neurol 11: 605-617.

11. McKenzie R, Travis W, Dolan S, Pittalug S, Feurstein I, et al. (1991) The causes of death in patients with human immunodeficiency virus infection: A clinical and pathologic study with emphasis on the role of pulmonary diseases. Medicine 70: 326-328.

12. De Gans J, Portegies P (1998) Neurological complications of infection with human immunodeficiency virus type I. A review of literature and 241 cases. Clin Neurol Neurosurg 91: 199-219.

13. Fuller GN, Guiloff RJ, Scaravilli F, Harcourt-Webster JN (1989) Combined HIV-CMV encephalitis presenting with brainstem signs. J Neurol Neurosurg Psychiatry 52: 975-979.

14. Holland NR, Power C, Mathews VP, Glass JD, Forman M, et al. (1994) Cytomegalovirus encephalitis in acquired immunodeficiency syndrome (AIDS). Neurology 44: 507-514.

15. Setinek U, Wondrusch E, Jellinger K, Steuer A, Drlicek M, et al. (1995) Cytomegalovirus infection of the brain in AIDS: a clinicopathological study. Acta Neuropathol 90: 511-515.

16. Maschke M, Kastrup O, Diener HC (2002) CNS manifestations of cytomegalovirus infections: diagnosis and treatment. CNS Drugs 16: 303-315.

17. Behar R, Wiley C, McCutchan J (1987) Cytomegalovirus polyradiculoneuropathy in acquired immune deficiency syndrome. Neurology 37: 557-61.

18. Cohen BA, McArthur JC, Grohman S, Patterson B, Glass JD (1993) Neurologic prognosis of cytomegalovirus polyradiculomyelopathy in AIDS. Neurology 43: 493-499.

19. Baig SM, Khan MA (1995) Cytomegalovirus-associated transverse myelitis in a non-immunocompromised patient. J Neurol Sci 134: 210-211.

20. Revello M, Percivalle E, Sarasini A, Baldanti F, Furione M, et al. (1994) Diagnosis of human cytomegalovirus infection of the nervous system by pp65 detection in polymorphonuclear leukocytes of cerebrospinal fluid from AIDS patients. J Infect Dis 170: 1275-1279.

21. Granter SR, Doolittle MH, Renshaw AA (1996) Predominance of neutrophils in the cerebrospinal fluid of AIDS patients with cytomegalovirus radiculopathy. Am J Clin Pathol 105: 364-366.

22. Clifford D, Arribas J, Storch G, Tourtellote W, Wippold F (1996) Magnetic resonance brain imaging lacks sensitivity for AIDS associated cytomegalovirus encephalitis. J Neurovirol 2: 397-403.

23. Miller R, Lucas S, Hall-Craggs M, Brink N, Scaravilli F, et al. (1997) Comparison of magnetic resonance imaging with neuropathological findings in the diagnosis of HIV and CMV associated CNS disease in AIDS. J Neurol Neurosurg Psychiatry 62: 346-351.

24. Silva C, Oliveira A, Vilas-boas L, Fink M, Pannuti C, et al. (2010) Neurologic cytomegalovirus complications in patients with AIDS: Retrospective review of 13 cases and review of the literature. Rev Inst Med Trop Sao Paulo 52: 305-310.

25. Anduze-Faris B, Fillet A, Gozlan J, Lancar R, Boukli N, et al. (2000) Induction and maintenance therapy of cytomegalovirus central nervous system infection in HIV-infected patients. AIDS 14: 517-524.

26. Berman SM, Kim RC (1994) The development of cytomegalovirus encephalitis in AIDS patients receiving ganciclovir. Am J Med 96: 415-419.

27. Cinquel P, Cleator G, Weber T, Monteyne P, Sindic C, et al. (1998) Diagnosis and clinical management of neurological disorders caused by cytomegalovirus in AIDS patients. European Union concerted action on virus meningitis and encephalitis. J Neurovirol 4: 120-132. 
Citation: Velagapudi M, Onaiwu C, Gupta V, Anthone J, Bricker L, et al. (2016) Cytomegalovirus (CMV) Encephalitis in HIV Patients. J Neurol Disord 4: 314. doi:10.4172/2329-6895.1000314

Page 3 of 3

28. Weinberg D, Murphy R, Naughton K (1994) Combined daily therapy with intravenous ganciclovir and foscarnet for patients with recurrent cytomegalovirus retinitis. Am J Ophthalmol 117: 776-782.

29. [No authors listed] (1996) Combination foscarnet and ganciclovir therapy vs monotherapy for the treatment of relapsed cytomegalovirus retinitis in patients with AIDS. The cytomegalovirus retreatment trial. The studies of ocular complications of AIDS Research Group in Collaboration with the AIDS Clinical Trials Group. Arch Ophthalmol 114: 23-33.

30. Biron KK (2006) Antiviral drugs for cytomegalovirus diseases. Antiviral Res 71: 154-163.

31. Holland GN (2008) AIDS and ophthalmology: the first quarter century. Am J Ophthalmol 145: 397-408.

32. Martin B, Ricks M, Forman M, Jabs D (2007) Cytomegalovirus Retinitis and Viral Resistance Study Group. Change over time in incidence of ganciclovir resistance in patients with cytomegalovirus retinitis. Clin Infect Dis 44: 1001-1008.

33. Lurain NS, Chou S (2010) Antiviral drug resistance of human cytomegalovirus. Clin Microbiol Rev 23: 689-712.

34. Chou S (2015) Approach to drug-resistant cytomegalovirus in transplant recipients. Curr Opin Infect Dis 28: 293-299.

35. Hakki M, Chou S (2011) The biology of cytomegalovirus drug resistance. Curr Opin Infect Dis 24: 605-611.

36. Drew WL (2010) Cytomegalovirus resistance testing: pitfalls and problems for the clinician. Clin Infect Dis 50: 733-736.
37. Le Page A, Jager M, Iwasenko J, Scott G, Alain S, et al. (2013) Clinical aspects of cytomegalovirus antiviral resistance in solid organ transplant recipients. Clin Infect Dis. 56: 1018-1029.

38. Mylonakis E, Kallas W, Fishman J (2002) Combination antiviral therapy for ganciclovir-resistant cytomegalovirus infection in solid-organ transplant recipients. Clin Infect Dis 34: 1337-1341.

39. West P, Schmiedeskamp M, Neeley H, Oberholzer J, Benedetti E, et al. (2008) Use of high-dose ganciclovir for a resistant cytomegalovirus infection due to UL97 mutation. Transpl Infect Dis 10: 129-132.

40. Kotton C, Kumar D, Caliendo A, Asberg A, Chou S, et al. (2013) Updated international consensus guidelines on the management of cytomegalovirus in solid-organ transplantation. Transplantation 96: 333360 .

41. Germi R, Mariette C, Alain S, Lupo J, Thiebaut A, et al. (2014) Success and failure of artesunate treatment in five transplant recipients with disease caused by drug-resistant cytomegalovirus. Antiviral Res 101: 57-61.

42. Verkaik N, Hoek R, Van Bergeijk H, Schipper M, Pas S, et al. (2013) Leflunomide as part of the treatment for multidrug-resistant cytomegalovirus disease after lung transplantation: Case report and review of the literature. Transpl Infect Dis 15: E243-E249.

43. Avery RK, Marty FM, Strasfeld L, Lee I, Arrieta A, et al. (2010) Oral maribavir for treatment of refractory or resistant cytomegalovirus infections in transplant recipients. Transpl Infect Dis 12: 489-496. 